\title{
Energy efficiency of optically backhauled LTE: a case study
}

\author{
(Invited Paper)
}

\author{
Slavisa Aleksic \\ Institute of Telecommunications \\ Vienna University of Technology \\ Favoritenstr. 9-11/E389, Vienna, Austria \\ slavisa.aleksic@tuwien.ac.at
}

\author{
Margot Deruyck and Wout Joseph \\ Department of Information Technology (INTEC) - iMinds \\ Ghent University \\ Gaston Crommenlaan 8, B-9050 Gent, Belgium \\ \{margot.deruyck, wout.joseph\}@intec.ugent.be
}

\begin{abstract}
Nowadays, we are witnesses of fast penetration of high data-rate cellular networks such as the Long Term Evolution (LTE). With increasing average access data rates in mobile networks, also the requirements on networks providing backhaul for the wireless infrastructure are increasing. New radio interfaces are already capable of providing hundreds of Mbps over a single radio link between a base station and a user, which means that the future backhaul network should be able to provide a connection to base station sites in the order of Gbps. As optical access networks are able to provide a very high bandwidth practically almost independent on distance as well as high energy efficiency, it seems that a combination of mobile wireless access with optical access networks is a very promising integrated approach for a sustainable and efficient next generation ubiquitous access network. Wireless cellular and optical wired access networks provide synergies and complementary features. The main benefits of using a kind of wireless access are mobility and ubiquity while optical access networks provide high data rates, low power consumption and robustness.

In this paper, we investigate various options for deploying LTE in urban areas with a particular emphasis on energy efficiency. For the purpose of evaluation, we apply an access network model to estimate both power consumption and achievable access data rates for various deployment scenarios and show results of a case study for the city of Vienna. The considered deployment scenarios are assessed regarding their potential for improving energy efficiency.
\end{abstract}

\section{INTRODUCTION}

Long Term Evolution (LTE) is one of the most emerging radio technologies nowadays [1]. It promises downlink peak rates of at least $100 \mathrm{Mbps}$ [2]. This is achieved by using among others SOFDMA (Scalable Orthogonal Frequency Division Multiple Access) as multiple access technique. SOFDMA is derived from OFDMA (Orthogonal Frequency Division Multiple Access) and supports a wide range of bandwidths to flexibly address the need for various spectrum allocation and application requirements. LTE supports variable bandwidths from $1.4 \mathrm{MHz}$ to $20 \mathrm{MHz}$ and operates in the $2.6 \mathrm{GHz}$ frequency range. In the future, LTE will probably also use the $800 \mathrm{MHz}$ band (digital dividend frequencies).

Additionally to the introduction of advanced radio interfaces there has been a constant increase of the number of active mobile subscribers worldwide [3]. The increase of both data rates per user of mobile networks and the number or users demands a higher capacity and a larger number of network terminals in the wireless backhaul network. Most of the conventional methods to provide backhaul to radio base stations such as microwave links, Time-Division Multiplexed (TDM) leased lines (E1/T1), Asynchronous Transfer Mode (ATM) or Digital Subscriber Lines (xDSL) are not capable of providing high data rates in the order of Gbps. Since optical access networks are able to provide very high data rates over long distances and a high energy efficiency [4-6], they seems to be best suitable for implementing a high-capacity and future-proven wireless backhaul.

There are different options for implementing optical access networks generally named as Fiber-To-The-x (FTTx) depending on how near to the subscriber the fiber reaches. A typical example is the Fiber-To-The-Home (FTTH), which means that the optical signal reaches the end subscriber's equipment situated in the subscriber home. Other examples are FTTB (Fiber-To-The-Building), FTTC (Fiber-To-The-Curb), and FTTN (Fiber-To-The-Node). The interconnections between network terminals and line terminals can be based on unidirectional or bidirectional fibers in a point-to-point (p-tp) or point-to-multipoint (p-t-mp) arrangement, the latter also named Passive Optical Network (PON).

There are various ways how to combine radio with optical fiber-based access technologies [7,8]. Maybe the most intuitive way would be to use the so-called radio over fiber (RoF) method, in which radio frequency signals are modulated directly on the optical carrier and transmitted through a fiber optic link. Different signals, frequency bands, modulation formats and coding schemes can be combined and transmitted over a single fiber [8]. Although this technique can potentially provide transparency in the optical domain to wireless standards and services and a high energy efficiency through minimizing the number of required components between the mobile user and central office of network providers, it suffers, however, from impairments on the signal such as noise, distortion, and dispersion. Additionally, even though considered as an option for the so-called converged next-generation FTTH networks, the currently deployed optical access infrastructure 
and devices do not support this option. Therefore, combining wireless access with a standard FTTH technology such as Gigabit PON (GPON), Ethernet PON (EPON) or p-t-p optical Ethernet seems to be the most probable option for an efficient short and medium term support of fast penetration of the highspeed LTE technology.

In this paper, we present a combined wireless/optical network model. The considered network architecture assumes the use of LTE for wireless access and a standard optical access technology for connecting the mobile base stations to the network core. The optical backhaul technologies we consider here are the point-to-point (p-t-p) Ethernet and the passive optical networks such as Gigabit PON (GPON) that is based on the Asynchronous Transfer Mode (ATM) or EPON based on the Ethernet. The network model is used to evaluate energy efficiency of an optically backhauled LTE on an example of a radio access network for the city of Vienna. The paper is organized as follows. In Section II, we describe the modeling method developed in the course of this study. Selected results are presented and discussed in Section III. Finally, we draw our conclusions in Section IV.

\section{NeTWORK MODEL}

The model comprises two submodels as presented in Fig. 1. The input parameters of the cellular wireless submodel are: area to be covered, population density, number of subscribers, percentage of subscribers that are active at each particular time, and down-stream (DS) and up-stream (US) data rates that are demanded by active users.

According to the technology and design related parameters and considering the usage of the network during the day, we obtain the actual aggregate traffic, and thus the actual average data rate per user for the cellular network submodel. The input parameters for the submodel of wireless backhaul are the outputs of the cellular submodel such as the average number of active users per cell, the number of active base stations and average data rates (both US and DS) per base station. Note that in case of a coexistence of two or more cell types, i.e., macro-, micro-, pico- and femtocells, the aforementioned parameters are given per cell type. Estimation of energy efficiency is done in the following three steps. First, design and configuration parameters are calculated according to the following input parameters: number of customers, area, technology peculiarities, aimed coverage, etc. Then, aggregate traffic at each network element is determined and the intermediate results are exchanged between the network submodels. Finally, average data rates and energy consumption are calculated and used to obtain the energy efficiency. The power consumption of network elements is determined by defining generic structures of each network element and summing up the values of power consumption at the component (subfunction) level. A detailed description of both the network and the energy consumption model can be found in [4,9-11].

The assumptions regarding network dimensioning and the number of mobile customers are made according to data for
TABLE I

MAIN ASSUMPTIONS AND PARAMETERS USED FOR MODELING A RADIO ACCESS NETWORK FOR THE CITY OF VIENNA.

\begin{tabular}{|c|c|}
\hline \multicolumn{2}{|c|}{ Scenario 1: baseline } \\
\hline Parameters & Value \\
\hline Area coverage & $\begin{array}{l}\text { - GSM/GPRS: } 95 \% \\
\text { - UMTS/EDGE: } 95 \% \\
\text { - LTE: } 2 \%\end{array}$ \\
\hline Backhaul type & $\begin{array}{l}\text { - } 95 \% \text { microwave } \\
\text { - } 4 \% \text { fiber } \\
\text { - } 1 \% \text { copper }\end{array}$ \\
\hline No. of sectors & $\begin{array}{l}\text { - } 1 \text { sector: } 2 \% \\
\text { - } 3 \text { sectors: } 97 \% \\
\text { - } 4 \text { sectors: } 1 \%\end{array}$ \\
\hline Cell diameter & $300 \mathrm{~m}-700 \mathrm{~m}$ \\
\hline Cell type & macro \\
\hline No. of network operators & 3 \\
\hline No. of sites (estimated/actual) & $2,568 / 2,571$ \\
\hline Average demanded data rate (DS/US) & 189/126 kbps (2012) \\
\hline
\end{tabular}

\begin{tabular}{|c|c|}
\hline \multicolumn{2}{|c|}{ Optically backhauled radio network (scenarios 2 to 4 ) } \\
\hline Parameters & Value \\
\hline Area coverage & $\begin{array}{l}\text { - GSM/GPRS: } 95 \% \\
\text { - UMTS/EDGE: } 95 \% \\
\text { - LTE: } 95 \%\end{array}$ \\
\hline Backhaul type & $\begin{array}{l}\text { - } 0 \% \text { microwave } \\
\text { - } 100 \% \text { fiber } \\
\text { - } 0 \% \text { copper }\end{array}$ \\
\hline No. of sectors & $\begin{array}{l}\text { - } 1 \text { sector: } 2 \% \\
\text { - } 3 \text { sectors: } 97 \% \\
\text { - } 4 \text { sectors: } 1 \%\end{array}$ \\
\hline Cell diameter & $300 \mathrm{~m}-700 \mathrm{~m}$ \\
\hline Cell type & macro \\
\hline No. of network operators & 3 \\
\hline No. of sites (estimated/actual) & $2,568 / 2,571$ \\
\hline Average demanded data rate (DS/US) & 1,7/1,2 Mbps (2016) \\
\hline
\end{tabular}

the city of Vienna that we obtained from the Statistics Austria [12], the Austrian Regulatory Authority for Broadcasting and Telecommunications (RTR), Austrian network operators and the Forum Mobilkommunikation (FMK); particularly, data on technology penetration, market shares and population statistics. The cell size is calculated according to population densities and intended maximum and average data rates to be provided to users within an area, i.e., within a city district. The range of a BS is determined by using appropriate propagation models $[13,14]$. The considered architecture of an optically backhauled radio access network and an exemplary coverage of the city of Vienna by a macrocell RAN are shown in Fig. 2.

\section{RESUlTS AND DISCUSSION}

Now we evaluate the energy efficiency of an exemplary radio access network. First, we define a baseline scenario in which we assume typical network design parameters for the 


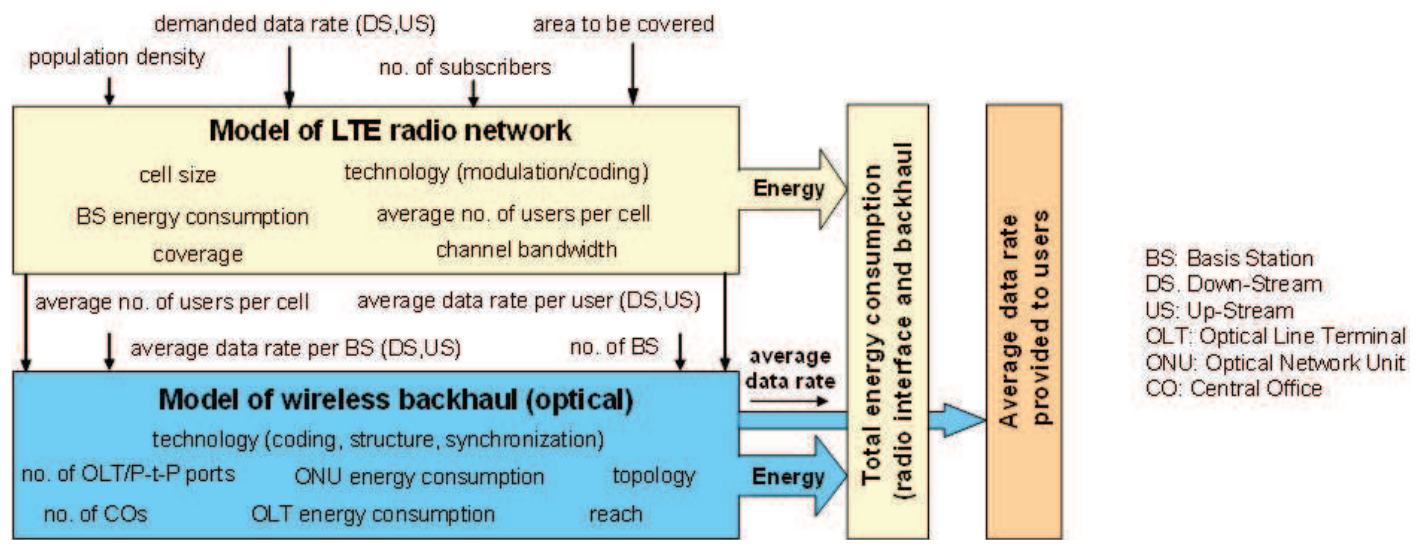

Fig. 1. Generic representation of the optically backhauled LTE network model

a)

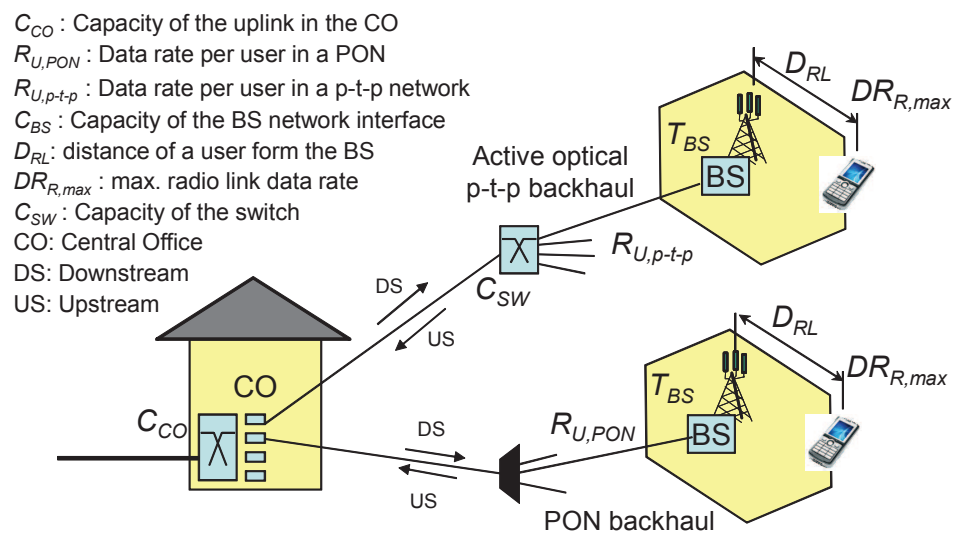

b)

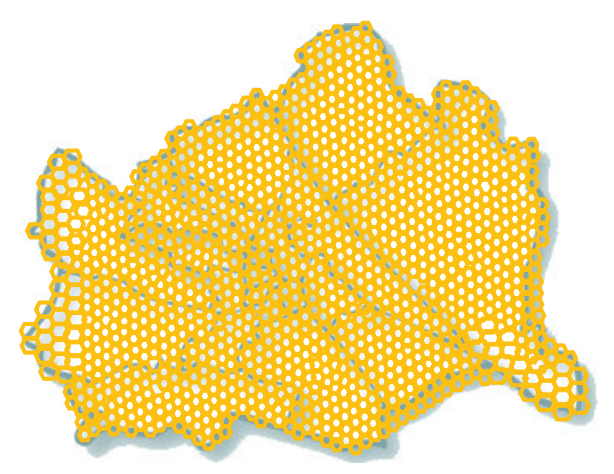

Fig. 2. a) Considered architecture of an optically backhauled radio access network and b) an exemplary coverage of the city of Vienna by macrocells.

city of Vienna. Then, we model GSM/GPRS, UMTS/EDGE and LTE radio access network with optical backhaul as shown in Fig. 2a). The main assumptions and parameters used for the model are listed in Table I.

Let us assume four deployment scenarios for an radio access network for Vienna. The first scenario is a baseline, which is described in the first part of Table I. For this scenario we assume an average demanded access data rate of 189/126 kbps for down-stream/up-stream (DS/US) directions [15]. The parameters for the other four scenarios (scenarios 2 to 4) are listed in the bottom part of Table I. These scenarios refer to a point in the future when LTE roll-out is completed as it could be the case in 2016. Therefore, we assume a higher average DS/US data rates per user of 1,7/1,2 Mbps as it has been projected for 2016 [15]. Main differences between scenarios 2 to 4 are the coverage and the choice of technology used for the radio access network. Accordingly, scenario 2 envisages a rollout of LTE with an optical backhaul using GPON technology, while the UMTS/EDGE network is phased out. Thus, there are coexisting GMS/GPRS and LTE networks, both with an optical backhaul. In scenario 3 the UMTS/EDGE network is still in operation in parallel to GSM/GPRS and LTE. Finally, scenario 4 envisages a phase-out of both GSM/GPRS and UMTS/EDGE networks, which are completely replaced by
TABLE II

A SUMMARY OF THE CONSIDERED SCENARIOS FOR LTE DEPLOYMENT.

\begin{tabular}{|c|c|c|}
\hline Scenario 2 & Scenario 3 & Scenario 4 \\
\hline GSM/GPRS: $95 \%$ & GSM/GPRS: 95\% & GSM/GPRS: 0\% \\
UMTS/EDGE: 0\% & UMTS/EDGE: 95\% & UMTS/EDGE: 0\% \\
LTE: 95\% & LTE: 95\% & LTE: $95 \%$ \\
GPON backhaul & GPON backhaul & GPON backhaul \\
\hline
\end{tabular}

an optically backhauled LTE network. Scenarios 2 to 4 are summarized in Table II.

The results of energy consumption and achievable average data rates for the four considered scenarios are shown in Fig. 3a). It is evident from the figure that deploying LTE with a high coverage additionally to the existing and operating GSM/GPRS and UMTS/EDGE networks would unavoidably lead to an increase in the total network energy consumption (see scenario 2). Even if all base station sites are optically backhauled the energy consumption increases by about $25 \%$ (from 86.6 to $109.3 \mathrm{GWh} / \mathrm{a}$ ). At the same time, a high LTE coverage enables an increase of data rates by a factor of 3.6. In the case when UMTS/EDGE infrastructure can be completely replaced by LTE (scenario 3 ) and an area-wide optical backhaul can be provided, the total energy consumption could even be slightly reduced to about $81 \mathrm{GWh} / \mathrm{a}$, which is an improvement of approximately $6 \%$ relative to the baseline 
a)

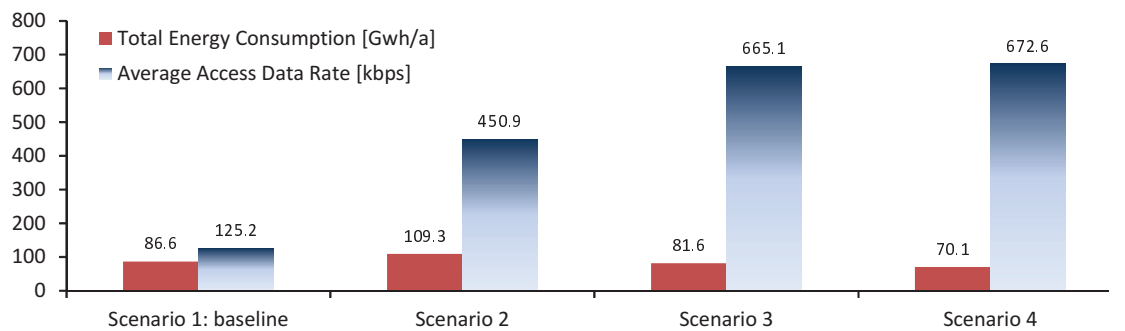

b)

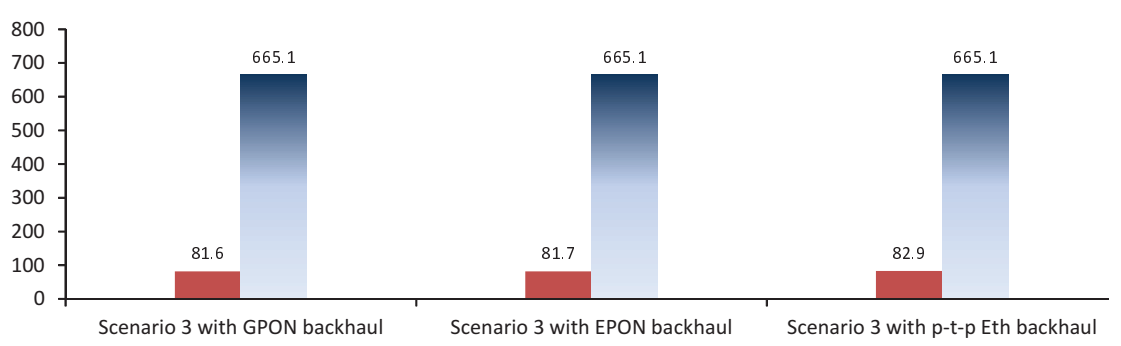

Fig. 3. Total energy consumption in GWh per year and achievable average access data rate a) for the four considered deployment scenarios and b) for different optical backhaul options.

scenario, while the average data rate increases by a factor of 5. Finally, if both GSM/GPRS and UMTS/EDGE networks could be phased-out and replaced by a high-coverage LTE network as assumed in scenario 4, the average data rate could be even further increased by a factor of 5.4 relative to the baseline scenario, while at the same time reducing the total energy consumption by more than $20 \%$.

The influence of the choice of the technology for optical wireless backhaul on energy efficiency is shown in Fig. 3b). Here we consider scenario 3 and estimate achievable average data rates and the total energy consumption when using either GPON or EPON or p-t-p active optical Ethernet for backhaul. As can be seen from the figure all three backhaul options are able to provide the same average data rate of approximately $665 \mathrm{kbps}$, while the energy consumption differs only insignificantly. The maximum relative difference in energy consumption between all three considered backhaul options is below $2 \%$.

\section{CONCLUSIONS}

In this paper, we presented a model for evaluation of energy efficiency of LTE radio access and optical backhaul networks. The model was applied to assess energy efficiency of several deployment scenarios for an example of optically backhauled LTE network for the city of Vienna. GPON, EPON and point-to-point optical Ethernet were considered as candidates for providing high-capacity backhaul to LTE radio access networks. Whilst optical backhaul is generally able to provide noticeable improvements in energy efficiency with regard to conventional backhauling methods, the influence of the choice of optical technology for backhaul is neglectable. Additionally, a transition to $4 \mathrm{G}$ LTE with a phase-out of $2 \mathrm{G}$ and/or $3 \mathrm{G}$ networks would result in a significant improvement of energy efficiency of radio access network infrastructure.

\section{REFERENCES}

[1] 3GPP LTE: 3rd Generation Partnership Project: Technical Specification Group Radio Access Network: Evolved Universal Terrestrial Radio Access (E-UTRA): User Equipment (UE) radio transmission and reception (TS 36.101 v9.1.0 Release 9. 2009.

[2] Akyildiz, I. F.; Gutierrez-Estevez, D. M.; Reyes, E. C. The evolution to 4G cellular systems: LTE-Advance. Elesevier Physical Communication 2010, 3, no. 4, DOI: 10.1016/j.phycom.2010.08.001, 217 - 244.

[3] International Telecommunication Union Telecommunication Standardization Sector (ITU-T) Statistics. 2012, http://www.itu.int/ITU-D/ict/ statistics/at_glance/KeyTelecom.html

[4] Aleksic, S.; Lovric, A. Energy Consumption and Environmental Implications of Wired Access Networks. American Journal of Engineering and Applied Sciences, Science Publications, 2012, 4, no. 4, 531 - 539.

[5] Aleksic, S. Energy Efficiency of Electronic and Optical Network Elements. (invited) IEEE JSTQE 2011, 17, no. 2-3, 296 - 308.

[6] Lovric, A.; Aleksic, S.; Lazaro, J. A.; Tosi Beleffi, G. M.; Bonada, F.; Prat, J. Influence of Broad-cast Traffic on Energy Efficiency of Long-Reach SARDANA Access Network. Optical Fiber Communication Conference (OFC) 2011, S5-2-1 - S5-2-6.

[7] Shen, G.; Tucker, R. S.; Chae, T. Fixed Mobile Convergence (FMC) Architectures for Broadband Access: Integration of EPON and WiMAX", IEEE Communications Magazine 2007, 44-50.

[8] Wake, D. Radio over Fiber Systems for Mobile Applications. in Radio over Fiber Technologies for Mobile Communications Networks, AlRaweshidy, H.; and Komaki, S. ed. Artech House, Inc 2002.

[9] Aleksic, S.; Deruyck, M.; Vereecken, W.; Joseph, W.; Pickavet, M.; Martens, L.; Energy Efficiency of Femtocell Deployment in Combined Wireless/Optical Access Networks. Elsevier Computer Networks 2013, 57, no. 5, DOI:10.1016/j.comnet.2012.12.013, 1217 - 1233.

[10] Aleksic, S.; Franzl, G.; Bogner, T.; Mair am Tinkhof, O. Framework for Evaluating Energy Efficiency of Access Networks. IEEE ICC'13 - GBA 2013, 1 - 6 .

[11] Deruyck, M.; Tanghe, E.; Joseph, W.; Martens, L. Modelling and Optimization of Power Consumption in Wireless Access Networks. Elsevier Computer Communications 2011, 34, no. 17, 2036 - 2046.

[12] Statistics Austria Demographic indices. 2012, http://www.statistik.at/ web_en/statistics/population/demographic_indices/index.html

[13] Erceg, V.; et al. An Empirically Based Path Loss Model for Wireless Channels in Suburban Environments. IEEE JSAC 1999, 17, 1205 - 1211.

[14] Recommendation ITU-R P.1238-2 Propagation data and prediction methods for the planning of indoor radiocommunication systems and radio local area networks in the frequency range $900 \mathrm{MHz}$ to $100 \mathrm{GHz} .2001$.

[15] Cisco Cisco Visual Networking Index: Global Mobile Data Traffic Forecast Update 20112016 White paper 2012, 1-29. 